\title{
Use of Nanomaterials in Food Science
}

\author{
Satish Kumar Ameta, Avinash Kumar Rai, Divya Hiran, \\ Rakshit Ameta, and Suresh C. Ameta
}

\begin{abstract}
The current global population is nearly 6 billion; due to this rapid population growth, there is a need to produce food in a more efficient, safe, and sustainable way, and it should be safe from the adverse effects of pathogenic organisms. A large proportion of population living in developing countries face daily food shortages as a result of environmental impacts or some other reasons like political instability, etc., while in the developed countries, food is surplus. For developing countries, the objective is to develop drought- and pest-resistant crops, with maximized yield. In developed countries, the food industry depends on consumer's demand for fresher and healthier foodstuffs. The present chapter describes the use of nanoparticles in food science.
\end{abstract}

\section{Keywords}

Nanomaterials $\cdot$ Food science $\cdot$ Food safety $\cdot$ Packaging

\footnotetext{
S. K. Ameta

Department of Environmental Science, Mewar University, Chittorgarh, Rajasthan, India
A. K. Rai · S. C. Ameta
Department of Chemistry, PAHER University, Udaipur, Rajasthan, India
D. Hiran
Department of Home Science, Government Meera Girls College, Udaipur, Rajasthan, India
R. Ameta $(\bowtie)$
Department of Chemistry, J. R. N. Rajasthan Vidyapeeth (Deemed to be University),
Udaipur, Rajasthan, India 


\subsection{Introduction}

The food market demands new technologies, which are essential to keep market leadership in the food processing industry to produce fresh, authentic, convenient, and flavorful food products, prolonging the product's shelf life and freshness with improved quality food (Alfadul and Elneshwy 2010). The new materials, products, and applications are anticipated to bring lots of advancements and improvements to the food and relevant sectors, impacting agriculture and food production, food processing, distribution, storage, nanoadditives, cleaning, and sensors for the detection of contaminants and developments of innovative products. Nanotechnology is an area of rising attention and unwraps new possibilities for the food industry. Nanotechnology integrates several disciplines, including physics, chemistry, biotechnology, and engineering.

There is a public opinion in general about nanotechnology applications, and it ranged from neutral to slightly positive one. There are suggestions that consumers should remain cautious about using nanofoods. The application of nanotechnology to the agricultural and food industries was first addressed by the US Department of Agriculture road map in September 2003 (Rashidi and Khosravi-Darani 2011). It has been predicted that nanotechnology will transform the complete food industry, changing all the way food is produced, processed, packaged, transported, and consumed. Food undergoes a variety of modifications in postharvest and processing that are likely to affect its biological and biochemical features, and here, nanotechnology developments could eventually also influence the food industry.

According to a definition in a report by the European Nanotechnology Gateway, a food is called nanofood when nanoparticles, or nanotechnology techniques, are used during cultivation, production, processing, or packaging of the food (Nanowerk 2019). It should be made clear here that it does not mean that it is atomically modified food or produced by nanomachines.

Applications of nano include smart packaging, on-demand preservatives, and interactive foods. Building on the concept of on-demand food, the idea of interactive food was to allow consumers to modify food depending on their own nutritional needs or tastes. There are many positive impacts of nanotechnology in the food industry, and these are expected to grow in the near future. Applications of nanomaterials will continue to affect the food industry commercially because of their unique and novel properties. New nanomaterials are developed that will make not only a difference in the taste of food but also safety and the health benefits that food is bound to deliver. This rapidly developing technology is concerned about every aspect of the food system starting from growth, packaging, processing, transportation, shelf life, and availability of nutrients. Therefore, nanotechnology may play a potential role in promoting the food industry. 


\subsection{Applications of Food Nanotechnology}

Nanotechnology is the science of very small materials, and it can have a big impact in the food industry. Nanotechnology possesses a great potential in ensuring modification of color and flavor and nutritional values, increasing the shelf life of food, and monitoring the integrity of food via barcodes such as cold chain, i.e., whenever there is a slight change in food storage conditions because of its submicroscopic nature (Aigbogun et al. 2017). It is an emerging area of science with potentials to generate radical new products and processes in the food sector. It is commonly distinguished between two forms of nanofood applications:

- Food additives (nano inside)

- Food packaging (nano outside)

Concepts in nanotechnology provide a sound framework for better understanding of the interactions and assembly behavior of food components into microstructures, which is likely to affect food structure, rheology, and functional properties at the submicroscopic scale (Sanguansri and Augustin 2006). It can also modify permeation of materials by the incorporation of synthesized nanoparticles (zinc, silver, gold, etc.) for improved packaging system (Fig. 24.1).

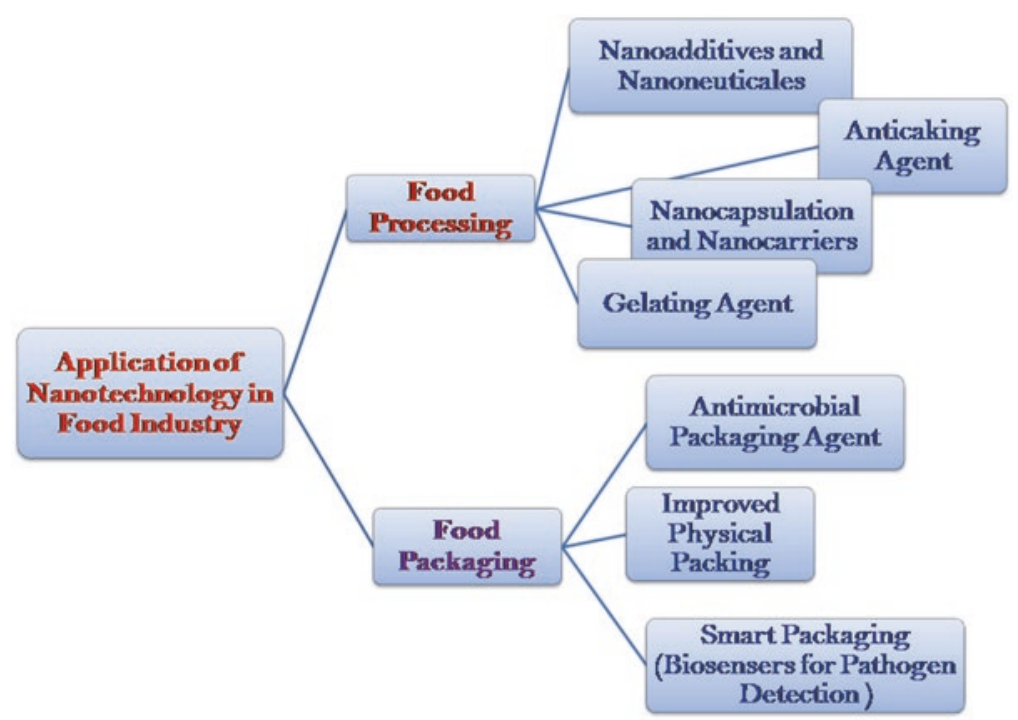

Fig. 24.1 Application of food nanotechnology 


\subsubsection{Food Processing}

Food processing deals with transformation of agricultural/animal products into food. It also includes many forms of processing foods ranging from grinding grain to make raw flour for home cooking to complex industrial methods used to make convenience foods. Food processing can be improved much in the aspects of smart delivery of nutrients, nanoencapsulation of nutraceuticals, bioseparation of proteins, rapid sampling of biological and chemical contaminants, solubilization, delivery, and color in food systems. These are some of the emerging uses of nanotechnology in food science (Ravichandran 2010). Nanotechnology can assist in the development of functional or interactive foods, which respond to requirements of the human body and can deliver these nutrients more efficiently. Various research groups are also developing new on-demand foods, which will remain dormant in the body and deliver nutrients to cells as and when needed. The concept is that thousands of nanocapsules containing flavor or color enhancers, or added nutritional elements (such as vitamins), would remain dormant in the food and these will be released only, when triggered by the consumer (Amin et al. 2015). A key element in this sector is the development of nanocapsules that can be incorporated into food to deliver nutrients timely. Other developments in food processing include the addition of nanoparticles to existing foods to enable increased absorption of nutrients. One of the bakeries in Western Australia is quite successful in incorporating tuna fish oil (a source of omega-3 fatty acids) in nanocapsules in their top-selling product "TipTop" Up bread (Bund 2008). The microcapsules are designed to break open only when they have reached the stomach, thus avoiding the unpleasant taste of the fish oil.

In this aspect, food and cosmetic companies are already working together to develop newer mechanisms to deliver vitamins directly to the skin. Nestlé, having $49 \%$ stake in L'Oréal, is developing transparent sun creams so that vitamin E is delivered directly to the skin. The major objective is to manufacture a cream which is first absorbed by the skin and then releases vitamin E slowly, apart from providing protection against UV. While Estée Lauder is manufacturing antiaging formulations making use of nanoparticles (Joseph and Morrison 2006), Unilever is developing ice creams with low fat by decreasing the size of emulsion particles, which is responsible for its texture. It is hoped that up to $90 \%$ less of the emulsion will be used and that will decrease fat content from $16 \%$ to about $1 \%$ (Verma and Gupta 2017).

\subsubsection{Nanosensors}

Nanosensors are devices that can measure physical quantities and convert those quantities to respective signals that can be detected and analyzed. These nanosensors are diagnostic devices to monitor the quality of food processes and also safety of food. Such nanosensors are used for the detection of very minute amounts of any chemical pollutant, virus, or bacteria in food systems. There is a possibility of combining biology with nanoscale technology in fabrication of sensors with a great potential of higher sensitivity and reduced response time. Nanoparticles may 
selectively attach themselves to food pathogens, and even traces of harmful pathogens could be detected with sensors using either infrared light or magnetic materials. It is advantageous that numerous nanoparticles can be placed on a single nanosensor so as to detect the presence of different bacteria and pathogens rapidly and accurately also. Another advantage is that nanosensors can gain access into the tiny crevices because of its small size, where the pathogens often used to hide, and nanotechnology will reduce the time taken for this detection from days to a few hours, minutes, or even seconds (Choudhury and Goswami 2012). Nanotechnology utilizes biological molecules like sugars or proteins as target-recognition groups for nanostructures as biosensors (Charych et al. 1996). These biosensors could serve as detectors of food pathogens and other contaminants and also to track food products.

Nanosensors may play a significant role in detection of any traces of pesticide available in various food products, providing a potent solution to food safety. These are of significant importance as such devices are capable for finding out and detect very minute quantity of organic compounds, very low concentration of pathogens, and other harmful chemicals. These devices show extraordinary sensitivity, quick response, and rescue (Otles and Yalcin 2010; Yalcin and Otles 2010). Mostly, nanosensors are used in recognition of pesticide as organophosphate in plants, fruits, and aquatics. It is known that pesticides are highly permeable and soluble and these are harmful. These are extensively used in agronomy. There is significant importance in analysis of residue of highly sensitive pollutants (Mclaren et al. 2009). Nanosensors devices have benefits over other techniques like gas/liquid chromatography and mass spectroscopy, because they contain high surface to volume ratios, primarily loading of more antibody/enzymes (great sensitivity interface), less recognition limits, exceptional selectivity with small size, and quick response. It has been known that the use of these nanosized materials is likely to enhance the sensitive transducer indication or signals. Carbon nanotubes semiconductor and metal nanostructures have exceptional electrical or optical characteristics (Hwang et al. 2011). Intelligent packing is another aspect, where covering a nano-biosensor makes these to fluoresce in various colors on interaction with different pathogens of food materials. Various types of devices have been developed to identify contaminants, chemicals, and pathogens in food materials. Such device is highly sensitive in identifying E. coli and Salmonella (Chen et al. 2008).

Traditional methods to screen food to find disease-causing microbes can take as long a day, which are normally very slow so that they may or may not be able to efficiently catch tainted products. However, some faster methods are known, but they have their own limitations. Magnetic resonance can detect extremely low levels of bacteria, but it is almost ineffective at higher bacteria concentrations, while fluorescence is opposite. A hybrid nanosensor incorporating magnetic resonance and fluorescence has been developed to rapidly detect the presence of $E$. coli (Banerjee et al. 2016). It has been reported that detector could sense different concentrations of a pathogenic strain of E. coli known as O157: H7 during test of milk in less than an hour. Such sensors will find the use in detecting environmental contamination control in the food sectors. 


\subsubsection{Interactive "Smart" Food Using Encapsulation}

Nanoencapsulation is a technology to pack substances in miniature using techniques like nanocomposite, nanoemulsification, and nanostructuration providing final product functionality that includes controlled release of the core (Sekhon 2010). Nanocapsules can be incorporated into food to deliver any nutrient. Addition of nanoparticles to existing food can also enable increased absorption of these nutrients (Jampilek et al. 2019). Nanoparticle additives could easily be absorbed by the body, and these could increase shelf life of the product. Nanosized dispersions, emulsions, and filled micelles have an advantage that they are not subjected to sedimentation resulting in better life span and storage of the product. As size of these nanoadditives is much smaller as compared to wavelength of light, they can be easily incorporated even in clear and transparent foods without causing problems of colors. Substances, which are difficult to dissolve by the body, can more easily be absorbed in nanoscale size, because of their larger surface area. If any active substance is to be protected during storage or its passage through the intestines, the nanotechnology can provide perfect protective layers. It is also possible to tailor these protective layers so as to release active substances in an intelligent way (caused by a change of $\mathrm{pH}$ value).

It may also be useful in protection against environmental factors and used in the design of food ingredients flavors and antioxidants (Imafidon and Spanier 1994). The main aim is to improve the functionality of such ingredients and keeping their concentration minimum. As the requirement of novel ingredients into foods is gaining popularity, better delivery and controlled release systems for nutraceuticals will be needed (Haruyama 2003; Lawrence and Rees 2000).

Bioactives, like coenzyme Q10 (CoQ10), vitamins, iron, calcium, curcumin, etc., have been widely tested in nanodelivery systems (He and Hwang 2016). Different nanodelivery vehicles have been developed such as association colloids, lipid-based nanoencapsulators/nanocarriers, nanoemulsions, biopolymeric nanoparticles, nanolaminates, nanofibers, etc. These nanodelivery systems can increase the bioavailability of bioactives by different pathways. Nanoencapsulation can enhance bioavailability of bioactive compounds after oral administration through targeted delivery systems. Such nanoencapsulation enables to control the release of flavors at the desired time and also to protect the degradation of these flavors during processing and storage (Yu et al. 2018).

Nowadays people are requiring more nutritional supplements because of the fact that many nutrients in food are being destroyed in the digestive tract. Each part presents a completely different environment, from oral cavity to the colon. In other words, there are a number of factors which decide the absorption of food in the body for infants, children, adults, old people, and those who are suffering from any type of gastrointestinal diseases. A nutrition delivery system is a system or nanocarrier that delivers nutrition to specific places. Chitosan is such a nanocarrier (Maestrelli et al. 2006). Although a delivery system has numerous functions, one of them is to transport a functional ingredient to its desired site. Just like taste, texture, and shelf 
life, major functions of a delivery system for a food product are that it should protect an ingredient from chemical or biological degradation, such as oxidation, and controlling the rate of release of functional ingredient under specific environmental conditions. Nanodispersions and nanocapsules are ideal mechanisms for delivery of functional ingredients because they can effectively perform all these tasks.

One of important part of the food industry is extracting nutrition from raw materials. Conventional methods for food processing are being replaced by newer techniques like nanotechnology, which will play a major role here. These techniques may improve food processing yields and decrease waste or spoilage of nutrition. Nutrition delivery systems must be prepared with biodegradable materials to prevent adverse effects on health of consumers. Some of the nanodelivery vehicles are as follows.

\subsection{Association Colloids}

A colloid system of a substance contains small particles dispersed throughout. An association colloid is the colloid, when particles are made up of even smaller molecules. It is already used to deliver polar, nonpolar, and amphiphilic functional ingredients (Golding and Sein 2004). The size of association colloids ranges between 5 and $100 \mathrm{~nm}$, and there are usually transparent solutions. Vesicles, bilayers, micelles, reverse micelles, and liquid crystals are some of the examples of association colloids. The major disadvantages of such colloids are that they may compromise with the flavor of the ingredients and these can spontaneously dissociate on dilution.

\subsection{Nanoemulsions}

An emulsion is a mixture of two or more liquids (such as oil and water) that are immiscible and, as such, do not easily combine. A nanoemulsion is an emulsion, when the diameters of the dispersed droplets is about $500 \mathrm{~nm}$ or even less than that. Nanoemulsions can encapsulate functional ingredients within their droplets facilitating a reduction in their chemical degradation (McClements and Decker 2000). Different types of nanoemulsions having more complex properties such as nanostructured multiple emulsions or nanostructured multilayer emulsions have multiple encapsulating abilities from a single delivery system that can carry several functional components. Here, a functional component is encased within one component of a particular multiple emulsion system, which could be released in response to a specific environmental trigger.

\subsection{Biopolymeric Nanoparticles}

Food-grade biopolymers like polysaccharides or proteins can be used to produce nanosized particles (Tak et al. 2015). A single biopolymer separates into smaller nanoparticles with aggregative (net attraction) or segregative (net repulsion) interactions. Nanoparticles can then be used to encapsulate functional ingredients and release them in response to particular environmental triggers. Most common 
components used biodegradable biopolymeric nanoparticles such as polylactic acid (PLA). PLA is quite commonly used to encapsulate and deliver drugs, vaccines, and proteins, but it has certain limitations:

- It is quickly removed from the bloodstream.

- It remains isolated in the liver and kidneys.

Therefore, PLA needs an associative compound such as polyethylene glycol to be successful in delivering active components to other areas of the body (Taylor et al. 2005).

\subsection{Nanolaminates}

Apart from nanodispersions and nanocapsules, nanolaminate is also a nanoscale technique, which is commercially used in the food industry. It consists of two or more layers of material with nano-dimensions, and it is an extremely thin foodgrade film (1-100 nm per layer), which has physically bonded or chemically bonded dimensions (Ravichandran 2010). A nanolaminate has a number of important applications in the food industry due to these advantages in the preparation of edible films. Such edible films are present on wide range of foods such as chocolate, candies, fruits, vegetables, meats, baked goods, French fries, etc. (Pavlath and Orts 2009). These films protect foods from gases, humidity, and lipids. They can also improve the textural properties of foods and serve as carriers of colors, flavors, nutrients, antioxidants, and antimicrobials.

Presently, these edible nanolaminates are prepared from polysaccharides, proteins, and lipids. Polysaccharide and protein-based films provide good protection against oxygen and carbon dioxide, but these are poor to protect against moisture. While lipid-based nanolaminates are significantly good to protect food from moisture, they have limited resistance to gases and show poor mechanical strength. Neither polysaccharides and proteins nor lipids provide all the properties in an edible coating and identify additives. Newer additives are searched that can improve these properties, e.g., polyols. Foods can be coated with nanolaminates either by dipping them into a series of solutions containing substances or by spraying substances onto the food surface (Shit and Shah 2014). The degree of adsorption of any substance depends on the nature of surface of food as well as on the nature of the adsorbing substance. Various adsorbing substances can form different layers of a nanolaminate; some of these are polyelectrolytes (proteins and polysaccharides), charged lipids, and colloidal particles. Different nanolaminates include varying functional agents such as flavors, colors, antimicrobials, anti-browning agents, antioxidants, enzymes, etc.

\subsection{Nanofibers and Nanotubes}

Nanotechnology has two more materials, which are likely to have an impact on the food industry. These are nanofibers and nanotubes. Nanofibers are usually not composed of food-grade substances; therefore, nanofibers have only fewer applications in the food industry. Nanofibers have small diameters in the size from 10 to $1000 \mathrm{~nm}$, 
which makes them ideal to serve as a platform for bacterial cultures (Guo 2015). These could also serve as the structural matrix for artificial foods and food packaging material, which are eco-friendly. As the efforts are growing in the area of producing nanofibers from food-grade materials, their use is likely to increase in the future. Similar to nanofibers, the use of nanotubes is mainly for nonfood applications. Carbon nanotubes are commonly used as low-resistance conductors and catalytic reaction vessels. Certain globular milk proteins can self-assemble into similarly structured nanotubes in some appropriate environmental conditions (GravelandBikker and de Kruif 2006).

\subsubsection{Antimicrobial Properties}

Microbial contamination is there due to pathogenic infections and poor nutrition associated with major types of food, but in particular weaning foods. Bacterial deterioration is one of the most discussed subjects as far as the production, processing, transport, and storing of food are concerned. Newer nano-antimicrobials have shown potential in safeguarding deterioration of food, and as a result, the shelf life of food is extended (Mitura and Zarzycki 2018). A number of metal and metal oxide nanomaterials have been reported to be effective as antimicrobials. Their physicochemical properties are considered responsible for excessive formation of reactive oxygen species (ROS), which leads to oxidative stress and subsequent cell damage (Fu et al. 2014; Wu et al. 2014).

Release of metal ions at all the places can affect cellular structure or function, whether it is outside the cell, at the cell surface, or within the cell. Metal or metal oxide-based nanocomposites are used in food packaging and coating or sometimes even as ingredients of food. Silver nanoparticles and its nanocomposites are most commonly used nanomaterials as antimicrobials in the food industry (He and Hwang 2016). The use of a number of silver-containing zeolites or similar substances as food contact materials has been approved by the USFDA for the purpose of disinfection (Duncan 2011). These nanoparticles are used as a source of $\mathrm{Ag}^{+}$ ions, which binds to membrane proteins, forming pits and/or causing other morphological changes (Morones et al. 2005). These also catalyze the generation of ROS in bacterial cells, which, in turn, leads to cell death through oxidative stress (Kim et al. 2007). It has been suggested that silver nanocomposites are quite safe for packaging of food, as no detectable or negligible levels of silver nanoparticles are released, which migrate from containers to actual food samples and food stimulants (Ntim et al. 2015). Nanocomposites have an advantage of enhanced stability, which is very much required for sustaining antimicrobial activity and reducing the possibility of migration of metal ions into stored foods. Some polymers are designed to form nanocomposites with metal/metal oxide nanomaterials for various applications in food science. Polymers most widely used in nanocomposites include gelatin, polylactic acid, isotactic polypropylene, and low-density polyethylene (LDPE). Nanocomposites of LDPE with metals (Ag/LDPE) and metal oxide (CuO/LDPE, $\mathrm{TiO}_{2} / \mathrm{LDPE}$, and $\left.\mathrm{ZnO} / \mathrm{LDPE}\right)$ are used in some food applications. Apart from these $\mathrm{ZnO} /$ gelatin, $\mathrm{ZnO}$ /polylactic acid, and $\mathrm{ZnO} /$ graphene oxide/polylactic acid, $\mathrm{ZnO}$ /polycarbonate, $\mathrm{ZnO} /$ isotactic polypropylene, $\mathrm{Ag} / \mathrm{OMteLDPE}$, and 
Ag/poly(3-hydroxybutyrate-co-18 mol\%-3-hydroxyvalerate) are also used specifically for food packaging applications (He and Hwang 2016). Polystyrene, polyvinylpyrrolidone, and poly(vinyl chloride) are also reported along with chitosan, as nanocomposite films, which binds to $\mathrm{Cu}$ or $\mathrm{ZnO}$ nanomaterials to control the growth of food pathogens or inactivate these ( $\mathrm{Li}$ et al. 2009).

\subsubsection{Protection Against Chemical Ingredients}

\subsection{Antioxidants}

As some metal/metal oxide nanomaterials cause oxidative stress through the formation of ROS (Manke et al. 2013), therefore, efforts were made to develop less reactive nanomaterials so that they can act as antioxidant carriers. Polymeric nanoparticles are considered suitable for the encapsulation of bioactive compounds such as flavonoids and vitamins, which are released in the stomach having acidic environments (Pool et al. 2012). $\mathrm{SiO}_{2}$-gallic acid nanoparticles were also developed, and these were tested as antioxidant with its scavenging capacity of DPPH (2,2-diphenyl-1-picrylhydrazyl) radicals (Deligiannakis et al. 2012). Browning of fresh-cut fruits is another problem, which can be controlled by the application of antioxidant treatments in association with edible coating, because browning of fresh-cut fruits is an undesirable effect due to conversion of phenolic compounds into some dark-colored pigments in the presence of oxygen (air), during storage and marketing (Garcia and Barrett 2019). But only some applications of nanomaterials directly as anti-browning agents have been known. The shelf life of Fuji apples (as a fresh-cut product) was enhanced using nano-ZnO-coated active packaging ( $\mathrm{Li}$ et al. 2011).

\subsubsection{Enhancement of Physical Properties}

\subsection{Color Additives}

A wide range of nanoscale color additives has been prepared and studied. These additives must be approved by the Office of Cosmetics and Colors in the Center for Food Safety and Applied Nutrition and the USFDA and used only for approved purpose, specifications, and of course restrictions (He and Hwang 2016). Certain such nanomaterial products have been duly approved to be used as food color additives. $\mathrm{TiO}_{2}$ is approved as a food color additive with the limit that it should not exceed 1\% w/w (Shi et al. 2013). It has also been permitted to use color additive mixtures made with $\mathrm{TiO}_{2}$ containing $\mathrm{SiO}_{2}$ and/or $\mathrm{Al}_{2} \mathrm{O}_{3}$ as dispersing aids, but their limit should not be more than $2 \%$ of the total.

\subsection{Flavors}

Flavors provide sensory perception of taste along with smell to stimulate appetite and eating experience, and therefore, it is one of the most important parts of the food system. Nanoencapsulation technique has been quite commonly used to improve release and retention of flavor and to deliver dietary balance (Nakagawa 2014). $\mathrm{SiO}_{2}$ nanomaterials can also act as carriers of these fragrances or flavors in food as well as nonfood products (Dekkers et al. 2011). 


\subsection{Anticaking Agents}

$\mathrm{SiO}_{2}$ is also used for thickening of pastes (as an anticaking agent) so as to maintain flow properties in powdered products along with as a carrier of fragrances or flavors in food and nonfood products. As a result, it has been used in food products and is registered within the EU as a food additive E551. However, still there is a debate regarding the health and safety issues related to the use of such engineered nanoparticles in consumer products (Athinarayanan et al. 2014).

\subsubsection{Packaging and Food Safety}

Food is a perishable item. It can be contaminated and/or degraded at any stage of the food chain. The process may be chemical, physical, or biological. The introduction/ presence of any pathogen in food can result in its poisoning, which can be deadly. Therefore, it is of utmost importance that the food must be protected at all levels. A good-quality packaging material is thus required, which is safe, nontoxic, and costeffective. Packaging using nanomaterial controls $\mathrm{pH}$, temperature, moisture, and freshness of the material kept inside the packet. It also contains information for consumers, along with controlling the environment to enhance the shelf life of the food material. It provides smart packaging and extends the shelf life of a product so that food material can be transported to a long distance also. Nanosensors are developed for smart packaging so as to detect spoilage of food and release nanoantimicrobials as and when required, to extend shelf life. It helps markets and in keeping the food fresh and that too for a longer period. There is a great demand for nano-enabled packaging for food, beverage, and pharmaceutical industries due to the regularly changing consumption patterns. Such nanopackaging systems can repair small losses like holes/tears because of environmental conditions (temperature and moisture) and make the customer alert if the food is being contaminated due to some or the other reasons. Nanoscience can provide solutions for such problems, change in permeation behavior of foils, enhancing barrier properties (like thermal, chemical, mechanical, and microbial), improving upon mechanical and heat resistance properties, introducing active antimicrobial and antifungal surfaces, and sensing/signaling any microbiological and biochemical changes that have occurred (Alfadul and Elneshwy 2010). Not only this, the cost of food additive ingredients can be lowered and the shelf life of food products can be increased using this technology. It is potential frontier of material science in packaging using nanomaterials. It has been estimated that advancement in nanotechnology supported by increased global investments has thrusted the nano-enabled packaging market all over the world in the past few years (Nano-enabled Packaging Market 2019).

About 400 companies and more than 400,000 scientists in the world are developing different nanotechnology applications in food and food packaging (Neethirajan and Jayas 2011). It has been estimated that nanotechnologies are projected to make use of nanomaterials of about US dollar 3 trillion by the year 2020 (Wesley et al. 2014). Here, smart packaging industry is growing relatively faster than predicted 
and is reaching maturity. The demand of consumer today is much more from packaging, particularly from protecting the quality, freshness, and safety of foods as well as convenience.

Several organizations have developed smart packaging systems. Researchers of Rutgers University have developed an electronic tongue for inclusion in packaging for Kraft Foods, which consists of an array of nanosensors extremely sensitive to gases released by spoiling food. They make sensor strip to change its color giving a clear signal, whether the food is fresh or not (World Bank 2017). A packaging film was developed by the Durethan KU2-2601, which is relatively lighter, stronger, and more heat resistant than those available currently in the market (Rani et al. 2017; Hamad et al. 2018). The main purpose of these food packaging films is to protect contents from drying out, moisture and oxygen. Such film is known as a hybrid system that contains number of silicate nanoparticles, thus reducing the entrance of oxygen and other gases and the exit of moisture, preventing food from spoiling.

Plastic bottles are normally used by breweries in shipping of beer, as these bottles are lighter than glass and low cost than metal cans. But, alcohol in beer reacts with the plastic of the bottles, which shortens the shelf life of alcohol to a great extent. Voridan has developed a nanocomposite in association with Nanocor, containing clay nanoparticles and named as Imperm (Srinivas 2016). These bottles are having both the qualities; these are lighter and stronger than glass and also less likely to shatter. It has been suggested that such nanocomposites structure minimizes the loss of carbon dioxide from the beer and the ingress of oxygen to the bottle, so as to keep the beer fresh up to a 6-month shelf life (Lua and Bowles 2013). Whatever may be the impacts of nanotechnology on the food industry and products entering the market, as the safety of food is the main concern, there is an urgent need to find new sensors, which will not only ensure food safety and security, but they will make customers and shopkeepers alert that a food is going to reach the end of its shelf life. Antimicrobial coatings and dirt repellent plastic bags are used ensuring the safety and security of packaged food. This will solve food shortage crises by ensuring that food reaches to masses in time and with good qualities (Hamad et al. 2018).

Nanosensors used in different food packaging industries include time-temperature integrator and gas detector (Pradhan et al. 2015). Nanoparticle in solution, nanoparticle-based sensors, array biosensors, electronic noses, nano-test strips, and nanocantilevers are among the different types of nanosensors used (Tang et al. 2009). Electronic noses are the type of sensor, which uses several chemical sensors attached to a data processing system (Vidhyalakshmi et al. 2009). Such sensor behaves just like our human nose, and therefore, this sensor is termed as electronic nose (e-nose). There are also reports of electronic tongue (e-tongue) sensors that are based on the principle of an electronic nose. The color is changed in contact with any sign of spoilage in the food material indicating that the food does not remain fit for consumption (Yuan et al. 2008). Packaging with such nanosensors can identify conditions of food and containers (internal and external) throughout the supply chain. Nanosensors can also detect gases in food, spoiled in plastic packaging, where a change in color of packaging alerts the consumer. 
A number of types of packaging materials are used in food sectors, which include active packaging, smart/intelligent packaging, edible coating, and biobased (biodegradable) polymeric films (Rai et al. 2018). Nanotechnology-driven food packaging has been categorized as follows.

\subsubsection{Active Packaging}

Active packaging means the use of active nanomaterials like antimicrobials and oxygen scavenging materials. The use of such nanomaterials is beneficial to interact directly with food to provide better protection to the product. Some nanomaterials can provide antimicrobial properties to food packaging. Some of them are nanosilver, nano-titanium dioxide, nano-magnesium oxide, nano-copper oxide, carbon nanotubes, etc. Active packaging utilizes the packaging materials, which interact with the environment, and food also and plays an active role in increasing the shelf life of products. It allows packages to play a dynamic role in food preservation. Advances made in active packaging leads to delayed oxidation, controlled respiration rate, microbial growth, and moisture migration (Brody 2006).

These packaging technologies include absorbers of carbon dioxide, odor, and ethylene and emitters of $\mathrm{CO}_{2}$ and aroma. But purging moisture control and oxygen removal remain prominent in active packaging, and out of these, purge control has been most successful on commercial scale. Best example is the use of drip-absorbing pad in the poultry industry (Suppakul et al. 2003). Active packaging technology also involves change in permselectivity (selective permeation) of package materials to different gases. Some nanocomposite materials have been used in active packaging so as to prevent oxygen, carbon dioxide, and moisture from reaching the food (Brody et al. 2008). An active system involving moisture scavenging has been quite commonly used particularly for packaging of dried and moisture-sensitive foods, while oxygen scavengers are normally inserted into the package in the form of small sachets just to reduce the oxygen level within the package, because an environment free from oxygen prevents oxidation of food as well as the growth of aerobic bacteria and mold. Ethylene-absorbing material is incorporated in packaging materials with the object of slowing the process of ripening and senescence of fruits and vegetables triggered by ethylene (Brody 2009).

Different antimicrobial agents are also incorporated in packaging so as to prevent the growth of spoilage and pathogenic microorganisms, which can directly influence the shelf life of products. It is more advantageous compared to direct addition of some antimicrobial agents onto foods either by sprays or drips. This packaging permits slow but a continuous release of antimicrobial agent from this packaging material to food surfaces, so that a high concentration of these agents is not there over a long period (Quintavalla and Vicini 2002). Different enzymes, bacteriocins, essential oils, anhydrides, and weak organic acids have also been investigated in terms of antimicrobial activity of food packaging systems (Corrales et al. 2014).

Improved packaging by nanomaterials involves mixing them into the polymer matrix, so as to improve the gas barrier properties and also resistance of the packaging against temperature and humidity. The US Food and Drug Administration has also approved the use of these nanocomposites in contact with food. 


\subsubsection{Smart/Intelligent Packaging}

Smart packaging is designed to sense any microbial or biochemical changes in the food products as it can detect the growth of any pathogens in the food. Some such smart packaging has been developed to be used as a tracking device for food safety. Presently, British Airways, MonoPrix supermarket, and Nestlé are using chemical sensors, which can quickly detect any color change (Pehanich 2006).

Nanotechnology has been used to manufacture a "smart" packaging, which can extend the shelf life of food dramatically, which permits it to be transported to a longer distance. Intelligent or smart packaging has been designed to monitor and communicate information about quality of food. It includes time-temperature indicators (TTIs), ripeness indicators, biosensors, and radio frequency identification. Such smart devices may be either incorporated in package materials itself or these are attached inside or outside of a package (Kerry et al. 2006; Yam et al. 2005; Kerry and Butler 2008). Smart packaging either responds to change in environmental conditions, repairs, or alerts the consumer about such contamination and/or the presence of some harmful pathogens. It is capable of detecting spoilage of food and release nanoantimicrobes to extend shelf life of food, so that supermarkets can keep their food materials even for a longer time periods before it is sold. Nanosensors are used as tiny chips invisible to the human eye, embedded into food products that act as electronic barcodes (Sekhon 2010).

Intelligent packaging is also developed, with specific preservative, which starts releasing preservatives as soon as food starts spoiling. Such "release on command" preservative packaging is based on a bio-switch. These are "smart" food packaging, which will warn, when oxygen has got inside or if food is being spoiled. These packaging are already in use in brewing and dairy industries. These consist of nanofilters, which can filter microorganisms and sometime even viruses. In some experiments, color was successfully removed from beetroot juice, but the flavor is not affected. Similarly red wine was turned into colorless or white in color. Lactose can also be filtered from milk, and it is replaced with some other sugar so that milk can be used by the lactose intolerant also. Nanoceramic particles are used for clustering of dirt molecules, so as to keep cooking oil fresh (Llobet et al. 2007; Wooster 2010). Nanotechnology has proved it worth in food safety by developing highly sensitive and low-cost nanosensors, which can respond to changes in environmental conditions during storage, degradation products, or contamination by microbes. Such nanosensors can be effectively used in packaging materials (Bouwmeester et al. 2014; Liao et al. 2005).

Time-temperature indicators (TTIs nanosensors) have been designed to monitor, record, and translate the safety of food. These TTIs allowed consumers to know about the quality of purchased materials. They also allow manufacturers to locate their foods along the supply line. A system based on gold nanoparticles for chilled foods has been developed by Timestrip. The system looks red above freezing temperature, but red color is lost because of agglomeration of the gold nanoparticles, when accidental freezing occurs (Robinson and Morrison 2010).

Gas sensors are also used for identification and quantification of various microorganisms, because they emit gas. Metal oxide gas nanosensor is most commonly 
used due to their high sensitivity and stability (Setkus 2002). Conducting polymers based nanosensors are also used because of their capability for identification and quantification of such microorganisms based on their gas emissions (Ahuja et al. 2007). Nontoxic and irreversible oxygen sensors were developed to assure the absence of oxygen in oxygen-free food packaging systems. Here, a UV-activated oxygen indicator was used, which is almost colorless on UV exposure, but blue color is restored in the presence of oxygen (Lee et al. 2002). Rapid, sensitive, and relatively low-cost diagnostic methods for detection of pathogens are being developed making use of unique magnetic, electrical, luminescent, and catalytic properties of nanomaterials (Merkoci 2010; Ayala-Zavala et al. 2014).

An electronic tongue or nose device has been fabricated, which consists of an array of nanosensors. Electronic nose (e-nose) has been developed for detecting freshness of fish (Oconnell et al. 2001), dairy products (off-flavor and rancidity of milk) (Ampuero and Bosset 2003; Marsili 1999, 2000; Capone et al. 2001), spoilage of red wine (Berna et al. 2008), red meat (El Barbri et al. 2008; Längkvist et al. 2013; Musatov et al. 2010), wine aging (Lozano et al. 2008), classification of different brands of coffee (Pardo et al. 2000), etc. These are extremely sensitive to gases released by spoiling microorganisms and produce change in color, indicating that the food is deteriorated. Such nanosensors could be placed directly into the packaging material (Liu et al. 2007; Lange et al. 2002). An electronic tongue developed by Kraft Foods (Smart Packaging systems, Glenview, IL, USA) may be incorporated in packaging. It also consists of an array of nanosensors, which are sensitive to gases released by spoiling food, and in that case, the sensor changes its color, giving a visible signal about freshness or adulteration of food (Momin et al. 2013). Electronic tongue (e-tongue) has been fabricated for determination of concentration of nitrite, nitrate, and chloride in minced meat (Campos et al. 2010), ripening of grapes (Campos et al. 2013), quality of tea (Kumar et al. 2016), polyphenols in wine (Andrei et al. 2016; Cetó et al. 2012; Magro et al. 2016), etc.

Silicate nanoparticles-packed films can control flow of oxygen into the pack as well as leakage of moisture out of the packings. It protects the package from being spoiled. The amount of packaging waste associated with processed food can also be reduced by using nanotechnology assisting in the preservation of fresh food.

\subsubsection{Carbon Nanotubes}

Food packaging materials are available ranging from films, carbon nanotubes, to waxy nano-coatings. Carbon nanotubes (CNTs) are available in both forms, singlewalled nanotube (SWCNT) and multiwalled nanotube (MWCNT). SWCNT is generally one atom thick, while MWCNT comprises of several concentric tubes with very high aspect ratios and elastic modulus. Asgari et al. (2014) reported that CNTs infused with polyethylene films can be used for the packaging of Mazafati dates, which can prevent fungal invasion up to 90 days. Carbon nanotubes have also been developed in packaging to pump out carbon dioxide or absorb undesirable flavors (Sinha et al. 2006). It has been known that CNTs also have antibacterial properties, which may be due to their direct penetration through microbial cells (Sharma et al. 2017). It has been reported that antimicrobial activity of silver nanoparticles against 
E. coli and B. cereus spores is significantly enhanced in combination with titanium dioxide and carbon nanotubes, respectively (Krishna et al. 2005). Ionic nanocomposites of carbon ceramic electrode with multiwalled carbon nanotubes may be used for the electrochemical determination of the adulterants in food and beverages such as food dyes, like sunset yellow, tartrazine, etc. In addition, carbon nanotubes have many other properties that may be exploited later on to develop the next generation of nanosensors. An important role is played by CNTs in food packaging and processing, but there may be some pitfalls, like these may migrate into food and contaminate it and can lead to toxic effects in human beings. The toxicity levels of CNTs are considerably high, and therefore, their use is limited.

\subsubsection{Biobased Packaging}

Nanotechnology can also be used for improving plastic substance barrier, incorporation of bioactive, sensing and signaling of important information about the food, for the change of the pervasion action of foils, growing different barrier characters (microbial, chemical, thermal, and mechanical), enhancing heat resistance and also mechanical characters (Berekaa 2015). It may also decrease the environmental contamination by making use of decomposable packaging based on biodegradable plastics.

These biodegradable plastics are basically polymeric materials, where at least one step in the degradation process is through metabolic process in the presence of some naturally occurring organisms. Disintegration or fragmentation of the plastics leads to biodegradation under desired conditions of moisture, temperature, and oxygen availability, without producing toxic or environmentally harmful materials (Chandra and Rustgi 1998). Such biodegradable polymers can be classified depending upon their source:

- Polymers, which are directly extracted or removed from biomass (i.e., polysaccharides, polypeptides, proteins, polynucleotides, etc.)

- Polymers, which are produced by classical chemical synthesis using some renewable biobased monomers or mixed sources of biomass and petroleum (polylactic acid or biopolyester)

- Polymers, which are produced by microorganism or genetically modified bacteria (polyhydroxybutyrate, bacterial cellulose, xanthan, curdian, pullan)

Various kinds of biodegradable polymer nanocomposites have been prepared with desired properties for a wide range of applications (Ray and Bousmina 2005). At present, the most commonly used biodegradable nanocomposites include starch and derivatives, polylactic acid (PLA), polybutylene succinate (PBS), polyhydroxybutyrate (PHB), and aliphatic polyester polycaprolactone, which are suitable for packaging purpose.

\subsection{Starch and Their Derivatives}

Starch is a potential raw material, because it is available from many plants. Its large production may fulfill current requirements, and it is low cost (Gonera and Cornillon 
2002), but it cannot form films with appropriate mechanical strength for a packaging material. So, it is first plasticized or chemically modified. It is converted to a thermoplastic material on treating in an extruder by application of both thermal and mechanical energy. Plasticizers play an important role in efficiently reducing intramolecular hydrogen bonds and also provide stability to properties of product, when thermoplastic starches are produced. Hence, there are ample opportunities that thermoplastic starches may be used as packaging material (Kim and Pometto 1994).

\subsection{Polylactic Acid (PLA)}

A wide range of biopolyesters can be prepared by conventional chemical synthesis. Presently, polylactic acid is the polymer, which has the highest potential as renewable packaging material, and it is commercially produced on major scale because lactic acid, a monomer of PLA, is easily produced by fermentation of carbohydrate feedstock (biomass). This feedstock can be obtained from a variety of agricultural products like wheat, maize, molasses, and whey. Biodegradable polylactic acid (PLA) polymer was evaluated for its use as a material for antimicrobial food packaging (Jin and Zhang 2008). They incorporated nisin in PLA films for controlling foodborne pathogens. Antimicrobial activity of PLA/nisin films was evaluated in liquid foods (orange juice and liquid egg white) against Listeria monocytogenes, Escherichia coli O157:H7, and Salmonella Enteritidis. Ramos et al. (2014) prepared nano-biocomposite films based on polylactic acid by incorporating thymol (as the active additive) and modified montmorillonite (D43B) at two different concentrations. It was observed that thermal stability was not significantly affected by the addition of thymol, but the incorporation of D43B improved its mechanical properties and reduced the oxygen transmission rate by the formation of intercalated structures. It was suggested that the formulated nano-biocomposites could be considered a potential antioxidant active packaging material.

\subsection{Polyhydroxybutyrate (PHB)}

Polylactic acid and polyhydroxybutyrate both offer a lot of opportunities in food packaging applications, because they are compatible with many foods, including dairy products, beverage, ready meals, and fresh meat products. It is accumulated by a large number of bacteria in the form of energy and carbon reserves. This biopolyester may also find industrial applications easily because of its biodegradability and biocompatibility (Van der Walle et al. 2001). Poly(lactic acid) and poly(hydroxybutyrate) were blended and plasticized by Arrieta et al. (2014) with a natural terpene D-limonene (LIM) so as to increase PLA crystallinity and to also obtain flexible films for food packaging applications. As-prepared materials were melt-blended and processed in transparent films. Disintegrability under composting conditions was also worked out, and it was reported that PHB delays the PLA disintegrability, but on the contrary, D-limonene speeds it up. Ma et al. (2018) developed poly(lactic acid)-poly(hydroxybutyrate) (PLA-PHB) based films containing bioactive elements and prepared seven formulations containing different contents of plasticizers (mono-caprylin glycerate (GMC) or glycerol monolaurate (GML)). Two formulations (PLA-PHB-based films with $0.5 \%$ GMC or GML) were selected, 
and 5\% cinnamaldehyde was added into each of these. It was revealed that PLAPHB-based films possessed better mechanical properties and better active properties on application to high lipid food simulant. This study showed that it is possible to use biodegradable active packing as an alternative to replace nonbiodegradable packaging for chilled salmon.

\subsection{Polycaprolactone (PCL)}

It is a biodegradable polyester having a low melting point around $60{ }^{\circ} \mathrm{C}$ only. It has some interesting applications in the fields of medical and agricultural areas (Nakayama et al. 1997). It has high elongation at break and low modulus. Apart from it, its physical properties and availability on commercial scale made it very attractive material for commodity applications. An antimicrobial nanopackaging was developed by Ahmed et al. (2019) for food application by incorporating zinc oxide nanoparticles and clove essential oil (CEO) into polylactide/polyethylene glycol polycaprolactone (PLA/PEG/PCL) blend. Here, CEO acts as an efficient plasticizer, which facilitates the chain mobility in the blend, as evident from tensile and thermal properties. The efficacy of these composite films was confirmed by using Staphylococcus aureus and Escherichia coli inoculated in scrambled egg. It was indicated that the PLA/PEG/PCL/ZnO/CEO film exhibited the highest antibacterial activity during 21 days storage at $4{ }^{\circ} \mathrm{C}$. Cesur et al. (2018) prepared antimicrobial and biodegradable food packaging films with polycaprolactone (PCL). The $0.4 \mathrm{wt} \%$ of organo nanoclay (C) and 25, 50, $75 \mathrm{wt} \%$ chitosan (K) and glycerol monooleate (GMO) or oleic acid (OA) as a plastifier $(5,10,20$, and $30 \mathrm{wt} \%)$ were added, and 12 polymeric composite films were prepared. The samples were coded as PCL (P), organo nanoclay $(\mathrm{C})$, oleic acid $(\mathrm{O})$, and glycerol monooleate $(\mathrm{G})$. The antimicrobial properties of these films were evaluated against Escherichia coli, Pseudomonas aeruginosa, Bacillus cereus, and Candida albicans. Polycaprolactone (PCL)/starch/ pomegranate rind (PR) hybrids were developed by Khalid et al. (2018) for antimicrobial packaging applications. PR was used as an antimicrobial compound, and it was incorporated directly in PCL matrix, without the extraction of any active compound from the fruit rind. It was revealed that PCL/PR films show reasonably good antimicrobial activity at higher concentrations. Addition of starch was found to enhance the antimicrobial activity of PR. As all the materials used here are biodegradable and food contactable, it has been suggested that the as-developed material could be used as food-grade antimicrobial packaging material.

Newer and newer nanomaterials have also been regularly developed, so that their physical and mechanical properties of packaging are improved, particularly in terms of tensile strength, water resistance, gas permeability, rigidity, flame resistance, etc. Due to such interesting properties, polymer nanocomposites are emerging as promising materials with a large capability for their applications in the active food packaging industry (Youssef 2013). 


\subsubsection{Types of Nanomaterials in Food}

Nanoparticles present in foods can be easily categorized based on their composition, (organic or inorganic), as this factor has a major impact on their gastrointestinal fate and potential toxicity (McClements and Xiao 2017).

\subsubsection{Inorganic Nanoparticles}

A number of nanoparticles used in food materials are mainly composed of some or the other inorganic materials, such as silver, silicon dioxide, iron oxide, titanium dioxide, or zinc oxide (Pietroiusti et al. 2016). These nanoparticles are either crystalline in nature or amorphous solids at ambient temperature. These may be spherical or nonspherical with different surface characteristics and sizes depending on precursor materials and conditions of preparation while these were fabricated. Such inorganic nanoparticles have different tendencies to dissolve under specific solution conditions ( $\mathrm{pH}$ and ionic strength) and also chemical reactivities, which have a major impact on their gastrointestinal fate and toxicity.

\subsection{Silver Nanoparticles}

Silver nanoparticles (AgNPs) are commonly used as antimicrobial agents in food packaging, chopping boards, storage containers, refrigerators, and health supplements. Silver nanoparticles are used for their antimicrobial effects in certain types of food containers by some manufacturer in the United States such as Kinetic Go Green basic nanosilver food storage container, Oso fresh food storage container, and FresherLonger ${ }^{\mathrm{TM}}$ Plastic Storage bags. It is also possible that some of these silver nanoparticles may migrate into foods from these containers and they could be ingested by humans (Echegoyen and Nerin 2013). Emamifar et al. (2011) prepared nanocomposite LDPE films containing $\mathrm{Ag}$ and $\mathrm{ZnO}$ nanoparticles via melt mixing in a twin screw extruder. Orange juice was sterilized and then inoculated with 8.5 $\log \mathrm{cfu} / \mathrm{mL}$ of Lactobacillus plantarum. They filled packages prepared from nanocomposite films with orange juice and then stored at $4{ }^{\circ} \mathrm{C}$. Microbial stability of the juice was evaluated after $7,28,56,84$, and 112 days of storage. It was reported that microbial growth rate significantly reduced on using this nanocomposite packaging material. A potential role of quantum sensors (QS) in food spoilage and food safety has been indicated (Naik and Kowshik 2014). Anti-QS materials like ATNPs were proposed as efficient models for controlling spoilage of food. Incorporation of ATNPs in food packaging materials could play an important role in preservation of food and ensure its safety by prolonging their shelf life. They proposed ATNPs as QS inhibitors with their potential use as an antipathogenic but nontoxic bioactive material. $\mathrm{Ag} / \mathrm{TiO}_{2}-\mathrm{SiO}_{2}$-coated food packaging film was developed also (Peter et al. 2015). Its ability to inactivate Botrytis cinerea was evaluated during the storage of fresh lettuce. Packaging film was prepared by coating the $\mathrm{Ag} / \mathrm{TiO}_{2}-\mathrm{SiO}_{2}$ ethanol suspension on polyethylene film. As-prepared packaging film was used for storage of green lettuce in a vegetation room. It was revealed that the shelf life of the lettuce 
stored in single- and double-layer film modified with $\mathrm{TiO}_{2}$ was extended by 4 and 2 days, respectively. It was revealed that the spoilage of the lettuce in double-layer film modified with $\mathrm{Ag} / \mathrm{TiO}_{2}-\mathrm{SiO}_{2}$ was lower after 5 days of storage than that of the lettuce stored in film modified with ethanol and unmodified film. Microbiological and chemical characteristics of white bread during storage in paper packages modified with $\mathrm{Ag} / \mathrm{TiO}_{2}-\mathrm{SiO}_{2}, \mathrm{Ag} / \mathrm{N}-\mathrm{TiO}_{2}$, or $\mathrm{Au} / \mathrm{TiO}_{2}$ have been investigated (Peter et al. 2016). The whiteness and the water retention of the modified packages were found to be slightly superior. The water retention was also observed to be very good, especially for the $\mathrm{Ag} / \mathrm{TiO}_{2}-\mathrm{SiO}_{2}$ paper. These improvements can be associated with the high specific surface area and with the low agglomeration tendency of Ag nanoparticles in comparison with the Au ones. Their use extends the shelf life of bread by 2 days except $\mathrm{Au} / \mathrm{TiO}_{2}$ as compared with the unmodified paper package.

\subsection{Zinc and Zinc Oxide Nanoparticles}

Zinc and zinc oxide nanoparticles may be used as an additive in supplements and functional foods for nutrition, because this is an essential trace element required to maintain human health and well-being. $\mathrm{ZnO}$ nanoparticles can also be used in food packaging as antimicrobial agents so that contamination of foods with harmful bacteria can be prevented (Sirelkhatim et al. 2015). These are also used as ultraviolet (UV) light absorbers to protect foods from UV light exposure, if food is sensitive toward it. The preparation of $\mathrm{ZnO}$ nanoparticles loaded starch-coated polyethylene film was reported (Tankhiwale and Bajpai 2012). This ZnO-loaded film was tested for its biocidal action against $E$. coli. As-developed material has a great potential to be used as food packaging material to prevent foodstuff from bacterial contamination. $\mathrm{TiO}_{2}$ and $\mathrm{ZnO}$ are biocompatible nanomaterials, and their biocompatibility was established through toxicity studies on cell lines (Venkatasubbu et al. 2016). Titanium dioxide and zinc oxide nanoparticle were synthesized by wet chemical process. The antibacterial activities of these materials were evaluated as food preservatives against Salmonella typhi, Klebsiella pneumoniae, and Shigella flexneri, and it was indicated that $\mathrm{TiO}_{2}$ and $\mathrm{ZnO}$ nanoparticles inhibited the growth of Salmonella, Klebsiella, and Shigella. It was revealed that the mode of their action is through generation of ROS in the case of Salmonella and Klebsiella, but it is still unclear in the case of Shigella.

\subsection{Titanium Dioxide Nanoparticles}

$\mathrm{TiO}_{2}$ nanoparticles are used as ingredients in foods to provide its characteristic optical properties, so that lightness and brightness are enhanced (Weir et al. 2012). It is widely used as food additive and antimicrobial agent for food packaging and storage containers. $\mathrm{TiO}_{2}$ ingredients utilized in the food industry as lightening agents should have particle sizes in the range of 100-300 nanometers, so that their lightscattering properties are increased. Six different coating suspensions were prepared, through mixing $\mathrm{TiO}_{2}$ (Aeroxide®P-25) nanoparticles (NPs) with three different types of binders [Shellac (A), polyuretahne (B), and polycrylic (C)] at a 1:4 to 1:16 NP to binder weight ratio (Yemmireddy and Hung 2015). They evaluated bactericidal activity of these $\mathrm{TiO}_{2}$ coatings against Escherichia coli $\mathrm{O} 157: \mathrm{H} 7$ at three 
different UV-A light intensities. $\mathrm{TiO}_{2}$ coatings with binder polyuretahne showed highest adhesion strength and scratch hardness as compared to coatings with other binders. It was found that $\mathrm{TiO}_{2}$ coatings with binder polycrylic were found to be physically more stable and able to retain their original bactericidal property on repeated use experiments $(1,3,5$, and 10 times).

\subsection{Silicon Dioxide Nanoparticles}

Silicon dioxide nanoparticles are used in certain powdered foods as anticaking agents. Silicon dioxide and carbon having particle size in the range of a few hundred $\mathrm{nm}$ are used as food additives and for food packaging.

\subsubsection{Organic Nanoparticles}

These nanoparticles are basically composed of organic substances, like carbohydrates, proteins, or lipids. These substances are liquids, semisolids, or solids (crystalline or amorphous) at ambient temperatures, which depends on their composition and processing conditions.

\subsection{Lipid Nanoparticles}

Lipid nanoparticles are present in a wide range within many commercial food products. These lipids and lipid nanoparticles are mostly used as oral delivery systems for different drugs and other active ingredients. Lipids usually increase drug absorption in the gastrointestinal tract (GIT). These molecules in the form of nanoparticles improve mucosal adhesion because of their small particle size and increase their residence time in GIT. Lipid nanoparticles will also protect the loaded drugs from different degradations (chemical as well as enzymatic) and release drug molecules from the lipid matrix gradually into blood, thus resulting in enhanced therapeutic profiles as compared to free drug (Severino et al. 2012).

\subsection{Protein Nanoparticles}

Protein nanoparticles and other protein assemblies have shown a great potential recently in the field of catalysis, materials synthesis, drug and gene delivery, and bio-imaging (Rong et al. 2011). Protein nanoparticles are also found in foods in the form of casein micelles, which are available in bovine milk and other dairy products. These are nothing but small clusters of casein molecules and calcium phosphate ions.

\subsection{Carbohydrate Nanoparticles}

Carbohydrate nanoparticles are either digestible or indigestible polysaccharides, like starch, cellulose, xanthan, carrageenan, alginate, and pectin.

\subsection{Complex Nanoparticles}

Nanoparticles utilized in foods are many a time fabricated using combinations of these three ingredients, such as lipids, proteins, and carbohydrates. Coacervates are formed by electrostatic complexation of oppositely charged proteins and polysaccharides. 


\subsubsection{Role in Tracking, Tracing, Nanolithography, and Brand Protection}

Nanotechnology is also helping food industries in providing authentication and track and trace features of a food product so that adulteration and diversion of products can be prevented (Nam et al. 2003). It is simply done by generating some complex invisible nanobarcodes with desired information, and it can be encrypted onto the food products and packaging. Such a nanobarcode detection system was created by $\mathrm{Li}$ et al. (2005) that produced fluorescence on exposure to ultraviolet light in a combination of color, which can be read by a computer scanner. This system has been tested on the food and some biological samples containing various pathogens like E. coli, anthrax, tularemia bacteria, and Ebola SARS viruses. These are also clearly indicated simultaneously by different color codes. Different codes can be created in the technology by altering the stripe orders, where every food item is assigned brand so that food batches can be traced.

\subsubsection{Implication and Safety Concerns}

Although there had been a rapid development in food nanotechnology using nanoparticles, little is known about the toxicity due to nanoparticles. Nanomaterials have some unique properties like high surface area, which makes them more active chemically than their bulk counterparts, and therefore, they could participate in most of the biological reaction having harmful effects on human health and/or environment. It is very much desired that nanostructures in food or related industries should not damage them directly or indirectly. Food and related industries have seen major changes due to unique properties of nanomaterials. But these unique properties may occasionally lead to dangerous side effects to ecosystems and even in people. There are two main safety concerns on using nanoparticles, and these are allergies and heavy metal release. At present, they are being used into food products at a relatively faster rate without desired knowledge and regulations, which can affect health and environment (Ranjan et al. 2014). It is necessary to take extra care while using nanomaterials as they may have potential toxic effects and their use in food science is increasing day by day. A report by the British Royal Society notes that we may face a nanotoxicity crisis in the future (Amini et al. 2014). Only with a proper detailed understanding of the properties of nanomaterials like size, solubility, surface chemistry, composition, etc., we will be in a position to find useful and safe food products. Of course, some of these unique properties of nanomaterials are making them wonderful materials, but sidewise, their use is also questionable at some or the other side.

\subsubsection{Size}

The size of nanoparticles is a very important feature for its unique properties as the surface area of nanoparticles depends upon its size. The effect of surface area on the respiration has been known as some nanoparticles are reported to cause pulmonary 
inflammation (Qiao et al. 2015). The toxicity of these nanoparticles not only depends on its chemical component, but it also depends on the quantity as well as position of the deposition. The size of particles is an important factor, which can be deciding for observing dermal-cell cytotoxicity in vitro. Such absorbed nanoparticles in different absorption routes could trigger an immune system response. The smaller size of these nanoparticles permits them to pass through different biological barriers. They can then settle in tissues like the central nervous system (CNS). Thus, the size of the nanoparticles is very important for safety purpose, whether such nanomaterials can be used in food and food-related industries or not.

\subsubsection{Chemical Composition}

Reagents used in the production of nanoparticles may be toxic. Some may remain in the final product and result in exposure to toxins that are unrelated to the nanomaterials themselves. For instance, some observed toxic effects of carbon nanotubes and semiconductor nanoparticles are related to residual reagents during synthesis. The remaining reagents and impurities may hinder our understanding of possible side effects of carbon nanotubes. Iron ions and impurities can accelerate the oxidative stress in cells. Crystallinity is another important aspect of chemical composition. Titanium oxide has three different levels of crystallinity that each has different cytotoxic effects (Suker and Albadran 2013).

\subsubsection{Surface Structure}

Cytotoxicity may also be affected from surfaces of nanostructures. Roughness, charge, hydrophobicity, and surface chemistry are the major factors that could affect the toxicological nature of absorbed nanoparticles in the human body (Kirchner et al. 2005). The toxic effects of nanoparticles can be controlled to some extent by coating nanoparticles with hydrophilic polymer like polyethylene glycol (PEG). It was indicated that positively charged nanoparticles were found to be more toxic as compared to negative or neutral nanoparticles.

\subsubsection{Solubility}

Solubility is also important in the toxicity of nanoparticles. Soluble titanium oxide nanoparticles (hydrophilic) are more toxic as compared to insoluble titanium oxide nanoparticles (Oberdörster 2001). Solubility of the toxicity of oxide nanoparticles has also been reported (Brunner et al. 2006).

\subsubsection{Routes of Nanoparticle Exposure}

There are different entry routes on exposure to nanoparticles such as dermal, respiratory, and digestive routes. These nanoparticles may enter the bloodstream after absorption and settle in different tissues like the brain or trigger some immune responses. Some genetic alteration has been also reported due to nanoparticles in food or nanoengineering of food (Bowman and Fitzharris 2007). Although there had been a long debate and it will go on, nanotechnology has entered into food packaging and food processing, so some safety measures are also required from governments and food producers. 
Some nanoparticles may be dispersed in the air during the production of nanoparticles used in food and related industries. This should be taken into consideration, and workers' health must be protected from respiratory tract uptake of nanoparticles. The digestive path is another major route of uptake of nanoparticles. Some nanoparticles may also enter in the respiratory tract and then the digestive system through mucociliary clearance. The skin is an alternate main route of contact between human and nanomaterials.

There are several diseases that are associated with exposure to nanoparticles due to their accumulation or contact with cells and its internal parts like the mitochondrion, nucleus, cytoplasm, membrane, and lipid vesicle (Buzea et al. 2007). Various diseases may be caused by nanoparticles, and these are

- Through inhalation

- Parkinson's disease

- Alzheimer's disease

- Asthma

- Bronchitis

- Cancer

- Arteriosclerosis

- Vasoconstriction

- Thrombus

- High blood pressure

- Heart disease

- Disease of unknown etiology in the kidneys and liver

- Podoconiosis

- Kaposi's sarcoma

- Through ingestion

- Crohn's disease

- Colon cancer

- Through skin contact

- Autoimmune diseases

- Dermatitis

- Urticaria

- Vasculitis

\subsection{Emerging Challenges and Potential Solutions}

With the developments in nanotechnology, its applicability to the food industry is likely to increase in the future. Of course, the success will depend on consumer acceptance. Various nanostructured materials (NSMs) ranging from inorganic metal, metal oxides, and their nanocomposites to nano-organic materials with bioactive agents have been applied in a wide range of food materials (Bajpai et al. 2018). Human exposure to these nanomaterials is regularly increasing, and its impact on health of the human and environment has become a point of public 
concern and interest. Although huge benefits are being offered by nanotechnology, the accumulation of nanostructured materials in human bodies and also in the environment has aroused several health and safety issues. This will require a uniform international regulatory framework for nanotechnology.

Different preparation technology could produce nanoparticles with different physical properties for their application in food. But, public perception regarding this new technology is still uncertain. Multiple guidelines of potential risks posed by nanomaterials have been released by different regulatory bodies like the US Environmental Protection Agency (USEPA), International Organization for Standardization and the Organization for Economic Cooperation and Development (IOSOECD), National Institute for Occupational Safety and Health (NIOSH), Health and Consumer Protection Directorate of the European Commission (HCPDEC), and Food and Drug Administration (FDA). It has been reported that these nanomaterials can improve food safety by increasing the efficacy of food packaging, shelf life, and nutritional value of food using additives without affecting the taste and physical characteristics of food products.

Nanotechnology is regularly gaining momentum; thus, it has become a very important tool for the food and bioprocessing industry to meet demands of increasing population growth all over the world. It has almost revolutionized conventional food science and food industry (He and Hwang 2016). It is also important to ascertain the toxicity of nanoparticles and the possible environmental and health hazards it may cause. Improvement in inorganic nanosubstance and microfluid manufacturing has permitted the preparation of effective and competent sensors to quickly detect/identify pathogens, microbes, or pesticides. The nanosensor or nanobiosensor should also be used in environmental contamination control in the food sectors. Functionalized food and nanosubstance should improve food value and protection as flavor and nutrient transporter.

It is still challenging to develop a healthy and sustainable food industry making use of nanoparticles in some or other forms. A large strength of the public is having a fear in using food engineered and genetically modified materials. Of course, one should be cautious in using nano-based materials in food science and the food industry but not afraid of its application. Although the fate and potential toxicity of nanomaterials are not fully known at this stage and such concerns require the education of public, ultimate success of such products will depend on acceptance by consumer. Time is not far off when nanofood technology will become a new frontier of this century, provided its harmful effects are fully controlled so that health and the environment are not adversely affected.

\section{References}

Ahmed J, Mulla M, Jacob H, Luciano G, Almusallam A (2019) Polylactide/poly( $\varepsilon$-caprolactone)/ zinc oxide/clove essential oil composite antimicrobial films for scrambled egg packaging. Food Packag Shelf Life 21:100355. https://doi.org/10.1016/j.fps1.2019.100355

Ahuja T, Mir IA, Kumar D, Rajesh (2007) Biomolecular immobilization on conducting polymers for biosensing applications. Biomaterials 28:791-805 
Aigbogun IE, Mohammed SSD, Orukotan AA, Tanko JD (2017) The role of nanotechnology in food industries- a review. J Adv Microbiol 7:1-9

Alfadul SM, Elneshwy AA (2010) USE of nanotechnology in food processing, packaging and safety - review. Afr J Food Agric Nutr Dev 10(6):2719-2739

Amin AA, Salama MF, Seliem EI, Mahmoud KF (2015) Encapsulation of nano carotenoids; evaluation of stability and safety. Int J Curr Microbiol App Sci 4(2):1017-1029

Amini SM, Gilaki M, Karchani M (2014) Safety of nanotechnology in food industries. Electron Physician 6(4):962-968

Ampuero S, Bosset JO (2003) The electronic nose applied to dairy products: a review. Sensors Actuators B Chem 94:1-12

Andrei V, Sharpe E, Vasilescu A, Andreescu S (2016) A single use electrochemical sensor based on biomimetic nanoceria for the detection of wine antioxidants. Talanta 156-157:112-118

Arrieta MP, López J, Hernández A, Rayón E (2014) Ternary PLA-PHB-limonene blends intended for biodegradable food packaging applications. Eur Polym J 50:255-270

Asgari P, Moradi O, Tajeddin B (2014) The effect of nanocomposite packaging carbon nanotube base on organoleptic and fungal growth of Mazafati brand dates. Int Nano Lett 4:1-5

Athinarayanan J, Periasamy VS, Alsaif MA, Al-Warthan AA, Alshatwi AA (2014) Presence of nanosilica (E551) in commercial food products: TNF-mediated oxidative stress and altered cell cycle progression in human lung fibroblast cells. Cell Biol Toxicol 30(2):89-100

Ayala-Zavala JF, González-Aguilar GA, Ansorena MR, Alvarez-Párrilla E, de la Rosa L (2014) Nanotechnology tools to achieve food safety. Chapter 17. In: Bhat R, Gomez-Lopez V (eds) Practical food safety: contemporary issues and future directions. Wiley-Blackwell, Oxford, pp 341-353

Bajpai VK, Kamle M, Shukla S, Mahato DK, Chandra P, Hwang SK, Kumar P (2018) Prospects of using nanotechnology for food preservation, safety, and security. J Food Drug Anal 26:1201-1214

Banerjee T, Sulthana S, Shelby T, Heckert B, Jewell J, Woody K, Karimnia V et al (2016) Multiparametric magneto-fluorescent nanosensors for the ultrasensitive detection of Escherichia coli O157:H7. ACS Infect Dis 2:667-673. https://doi.org/10.1021/acsinfecdis.6b00108

Berekaa MM (2015) Nanotechnology in food industry; advances in food processing, packaging and food safety. Int J Curr Microbiol App Sci 4(5):345-357

Berna AZ, Trowell S, Cynkar W, Cozzolino D (2008) Comparison of metal oxide based electronic nose and mass spectrometry based electronic nose for the prediction of red wine spoilage. $\mathrm{J}$ Agric Food Chem 56:3238-3244

Bouwmeester H, Brandhoff P, Marvin HJP, Weigel S, Peters RJB (2014) State of the safety assessment and current use of nanomaterials in food and food production. Trends Food Sci Technol 40(2):200-210

Bowman DM, Fitzharris M (2007) Too small for concern? Public health and nanotechnology. Aust N Z J Public Health 31(4):382-384

Brody A (2006) Nano and food packaging technologies converge. Food Technol 60(3):92-94

Brody AL (2009) Innovations in fresh prepared meal delivery systems. Food Technol 63:84-86

Brody AL, Bugusu B, Han JH, Sand CK, Mchugh TH (2008) Scientific status summary-innovative food packaging solutions. J Food Sci 73(8):R107-R116

Brunner TJ, Wick P, Manser P, Spohn P, Grass RN, Limbach LK, Bruinink A et al (2006) In vitro cytotoxicity of oxide nanoparticles: comparison to asbestos, silica, and the effect of particle solubility. Environ Sci Technol 40(14):4374-4381

Bund (2008) Ausdem Labor auf den Teller: Die Nutzung der Nanotechnologie im Lebensmittelsektor. https://www.bund.net/fileadmin/user_upload_bund/publikationen/chemie/ nanotechnologie_aus_dem_labor_auf_den_teller.pdf. Accessed on 25 May 2019

Buzea C, Pacheco II, Robbie K (2007) Nanomaterials and nanoparticles: sources and toxicity. Biointerphases 2(4):17-71

Campos I, Masot R, Alcañiz M, Gil L, Soto J, Vivancos JL, Martínez-Mañez R et al (2010) Accurate concentration determination of anions nitrate, nitrite and chloride in minced meat using a voltammetric electronic tongue. Sensors Actuators B Chem 149(1):71-78 
Campos I, Bataller R, Armero R, Gandia JM, Soto J, Martínez-Máñez R, Gil-Sánchez L (2013) Monitoring grape ripeness using a voltammetric electronic tongue. Food Res Int 54(2):1369-1375

Capone S, Epifani M, Quaranta F, Siciliano P, Taurino A, Vasanelli L (2001) Monitoring of rancidity of milk by means of an electronic nose and a dynamic PCA analysis. Sensors Actuators B Chem 78:174-179

Cesur S, Köroğlu C, Yalçın HT (2018) Antimicrobial and biodegradable food packaging applications of polycaprolactone/organo nanoclay/chitosan polymeric composite films. J Vinyl Addit Technol 24:376-387

Cetó X, Céspedes F, Pividori MI, Gutiérrez JM, del Valle M (2012) Resolution of phenolic antioxidant mixtures employing a voltammetric bio-electronic tongue. Analyst 137:349-356

Chandra R, Rustgi R (1998) Biodegradable polymers. Prog Polym Sci 23:1273-1335

Charych D, Cheng Q, Reichert A, Kuziemko G, Stroh N, Nagy J, Spevak W et al (1996) A 'litmus test' for molecular recognition using artificial membranes. Chem Biol 3:113-120

Chen Y, Cheng JJ, Creamer KS (2008) Inhibition of anaerobic digestion process: a review. Bioresour Technol 99(10):4044-4064

Choudhury SR, Goswami A (2012) Supramolecular reactive sulphur nanoparticles: a novel and efficient antimicrobial agent. J Appl Microbiol 114:1-10

Corrales M, Fernandez A, Han JH (2014) Antimicrobial packaging systems. In: Han J (ed) Innovations in food packaging. Elsevier, Amsterdam, pp 133-169

Dekkers S, Krystek P, Peters RJ, Lankveld DX, Bokkers BG, van Hoeven-Arentzen PH, Bouwmeester $\mathrm{H}$ et al (2011) Presence and risks of nanosilica in food products. Nanotoxicology 5:393-405

Deligiannakis Y, Sotiriou GA, Pratsinis SE (2012) Antioxidant and antiradical SiO2 nanoparticles covalently functionalized with gallic acid. ACS Appl Mater Interfaces 4:6609-6617

Duncan TV (2011) Applications of nanotechnology in food packaging and food safety: barrier materials, antimicrobials and sensors. J Colloid Interface Sci 363:1-24

Echegoyen Y, Nerin C (2013) Nanoparticle release from nano-silver antimicrobial food containers. Food Chem Toxicol 62:16-22

El Barbri N, Llobet E, El Bari N, Correig X, Bouchikhi B (2008) Electronic nose based on metal oxide semiconductor sensors as an alternative technique for the spoilage classification of red meat. Sensors 8:142-156

Emamifar A, Kadivar M, Shahedi M, Soleimanian-Zad S (2011) Effect of nanocomposite packaging containing $\mathrm{Ag}$ and $\mathrm{ZnO}$ on inactivation of Lactobacillus plantarum in orange juice. Food Control 22:408-413

Fu PP, Xia Q, Hwang HN, Ray PC, Yu H (2014) Mechanisms of nanotoxicity: generation of reactive oxygen species. J Food Drug Anal 22:64-75

Garcia E, Barrett DM (2019) Preservative treatments for fresh cut fruits and vegetables. http:// www.fruitandvegetable.ucdavis.edu/files/217061.pdf. Accessed on 23 May 2019

Golding M, Sein A (2004) Surface rheology of aqueous casein-monoglyceride dispersions. Food Hydrocoll 18:451-461

Gonera A, Cornillon P (2002) Gelatinization of starch/gum/sugar systems studied by using DSC, NMR, and CSLM. Starch-Starke 54(11):508-516

Graveland-Bikker JF, Kruif de CG (2006) Unique milk protein based nanotubes: food and nanotechnology meet. Trends Food Sci Technol 17(5):196-203

Guo KW (2015) Current relevant nanotechnologies for the food industry. In: Bagchi D, Swaroop A, Bagchi M (eds) Genomics, proteomics and metabolomics in nutraceuticals and functional foods. Wiley, Chichester, p 629

Hamad AF, Han JH, Kim BC, Rather IA (2018) The intertwine of nanotechnology with the food industry. Saudi J Biol Sci 25:27-30

Haruyama T (2003) Micro- and nanobiotechnology for biosensing cellular responses. Adv Drug Deliv Rev 55:393-401

He X, Hwang HM (2016) Nanotechnology in food science: functionality, applicability, and safety assessment. J Food Drug Anal 24:671-681 
Hwang SH, Park YB, Yoon KH, Bang DS (2011) Smart materials and structures based on carbon nanotube composites. In: Yellampalli S (ed) Carbon nanotubes - synthesis, characterization, applications. InTech, Rijeka. ISBN: 978-953-307-497-9, Available from: file://C:/Users/hp/ Downloads/16812.pdf. Accessed 20 May 19

Imafidon GI, Spanier AM (1994) Unraveling the secret of meat flavor. Trends Food Sci Technol 5:315-321

Jampilek J, Kos J, Kralova K (2019) Potential of nanomaterial applications in dietary supplements and foods for special medical purposes. Nano 9:pii: E296. https://doi.org/10.3390/ nano9020296

Jin T, Zhang H (2008) Biodegradable polylactic acid polymer with nisin for use in antimicrobial food packaging. J Food Sci 73(3):M127-M134. https://doi.org/10.1111/j.1750-3841.2008.00681.x

Joseph T, Morrison M (2006) Nanoforum report: nanotechnology in agriculture and food. https://nanotech.law.asu.edu/Documents/2009/09/nanotechnology_in_agriculture_and_ food_234_2644.pdf. Accessed on 25 May 2019

Kerry J, Butler P (2008) Smart packaging technologies for fast moving consumer goods. Wiley, Chichester

Kerry JP, O'Grady MN, Hogan SA (2006) Past, current and potential utilization of active and intelligent packaging systems for meat and muscle-based products: a review. Meat Sci 74:113-130

Khalid S, Yu L, Feng M, Meng L, Bai Y, Ali A, Chen L et al (2018) Development and characterization of biodegradable antimicrobial packaging films based on polycaprolactone, starch and pomegranate rind hybrids. Food Packag Shelf Life 18:71-79. https://doi.org/10.1016/j. fps1.2018.08.008

Kim M, Pometto AL (1994) Food packaging potential of some novel degradable starchpolyethylene plastics. J Food Prot 57(11):1007-1012

Kim JS, Kuk E, Yu KN, Kim JH, Park SJ, Lee HJ, Kim SH et al (2007) Antimicrobial effects of silver nanoparticles. Nanomed Nanotechnol Biol Med 3:95-101

Kirchner C, Liedl T, Kudera S, Pellegrino T, Muñoz JA, Gaub HE, Stölzle S et al (2005) Cytotoxicity of colloidal CdSe and CdSe/ZnS nanoparticles. Nano Lett 5(2):331-338

Krishna V, Pumprueg S, Lee SH, Zhao J, Sigmund W, Koopman B, Moudgil BM (2005) Photocatalytic disinfection with titanium dioxide coated multi- wall carbon nanotubes. Process Saf Environ Prot 83:393-397

Kumar AS, Shanmugam R, Nellaiappan S (2016) Chemical tea quality assessment by analyzing key polyphenolic functional groups using flow injection analysis coupled with a dual electrochemical detector. Sensors Actuators B Chem 227:352-361

Lange D, Hagleitner C, Hierlemann A, Brand O, Baltes H (2002) Complementary metal oxide semiconductor cantilever arrays on a single chip: mass-sensitive detection of volatile organic compounds. Anal Chem 74(13):3084-3095

Längkvist M, Coradeschi S, Loutfi A, Rayappan JBB (2013) Fast classification of meat spoilage markers using nanostructured $\mathrm{ZnO}$ thin films and unsupervised feature learning. Sensors (Basel) 13:1578-1592

Lawrence MJ, Rees GD (2000) Microemulsion-based media as novel drug delivery systems. Adv Drug Deliv Rev 45:89-121

Lee SW, Mao C, Flynn CE, Belcher AM (2002) Ordering of quantum dots using genetically engineered viruses. Science 296:892-895

Li Y, Cu Y, Luo D (2005) Multiplexed detection of pathogen DNA with DNA based fluorescence nanobarcodes. Nat Biotechnol 23:885-889

Li X, Xing Y, Jiang Y, Ding Y, Li W (2009) Antimicrobial activities of ZnO powder-coated PVC film to inactivate food pathogens. Int J Food Sci Technol 44:2161-2168

Li X, Li W, Jiang Y, Ding Y, Yun J, Tang Y, Zhang P (2011) Effect of nano-ZnO-coated active packaging on quality of fresh-cut 'Fuji' apple. Int J Food Sci Technol 46:1947-1955

Liao F, Chen C, Subramanian V (2005) Organic TFTs as gas sensors for electronic nose applications. Sensors Actuators 107:849-855

Liu Y, Chakrabartty S, Alocilja E (2007) Fundamental building blocks for molecular biowire based forward error-correcting biosensors. Nanotechnology 18:1-6 
Llobet E, Gualdrón O, Vinaixa M (2007) Efficient feature selection for mass spectrometry based electronic nose applications. Chemom Intell Lab Syst 85(2):253-261

Lozano J, Arroyo T, Santos JP, Cabellos JM, Horrillo MC (2008) Electronic nose for wine ageing detection. Sensors Actuators B Chem 133:180-186

Lua J, Bowles M (2013) How will nanotechnology affect agricultural supply chains? Int Food Agribusiness Manag Rev 16(2):21-42

Ma Y, Li L, Wang Y (2018) Development of PLA-PHB-based biodegradable active packaging and its application to salmon. Packag Technol Sci 31(11):739-746

Maestrelli F, Garcia-Fuentes M, Mura P, Alonso MJ (2006) A new drug nanocarrier consisting of chitosan and hydoxypropylcyclodextrin. Eur J Pharm Biopharm 63(2):79-86

Magro M, Bonaiuto E, Baratella D, de Almeida Roger J, Jakubec P et al (2016) Electrocatalytic nanostructured ferric tannates: characterization and application of a polyphenol nanosensor. ChemPhysChem 17:3196-3203

Manke A, Wang L, Rojanasakul Y (2013) Mechanisms of nanoparticle-induced oxidative stress and toxicity. Biomed Res Int 2013:942916. https://doi.org/10.1155/2013/942916

Marsili RT (1999) SPME-MS-MVA as an electronic nose for the study of off-flavors in milk. J Agric Food Chem 47:648-654

Marsili RT (2000) Shelf-life prediction of processed milk by solid-phase microextraction, mass spectrometry, and multivariate analysis. J Agric Food Chem 48:3470-3475

McClements DJ, Decker EA (2000) Lipid oxidation in oil-in-water emulsions: impact of molecular environment on chemical reactions in heterogeneous food systems. J Food Sci 65:1270-1282

McClements DJ, Xiao H (2017) Is nano safe in foods? Establishing the factors impacting the gastrointestinal fate and toxicity of organic and inorganic food-grade nanoparticles. NPJ Sci Food 1:6. https://doi.org/10.1038/s41538-017-0005-1

Mclaren A, Valdes-Solis T, Li G, Tsang SC (2009) Shape and size effects of ZnO nanocrystals on photocatalytic activity. J Am Chem Soc 131(35):12540-12541

Merkoci A (2010) Nanoparticles-based strategies for DNA, protein and cell sensors. Biosens Bioelectron 26(4):1164-1177

Mitura KA, Zarzycki PK (2018) Biocompatibility and toxicity of allotropic forms of carbon in food packaging. In: Grumezescu AM, Holban AM (eds) Role of materials science in food bioengineering. Academic, London, p 93

Momin JK, Jayakumar C, Prajapati JB (2013) Potential of nanotechnology in functional foods. Emirates J Food Agric 25(1):10-19

Morones JR, Elechiguerra JL, Camacho A, Holt K, Kouri JB, Ramírez JT, Yacaman MJ (2005) The bactericidal effect of silver nanoparticles. Nanotechnology 16:2346-2353

Musatov VY, Sysoev VV, Sommer M, Kiselev I (2010) Assessment of meat freshness with metal oxide sensor microarray electronic nose: a practical approach. Sensors Actuators B Chem 144:99-103

Naik K, Kowshik M (2014) Anti-quorum sensing activity of $\mathrm{AgCl}^{-\mathrm{TiO}_{2}}$ nanoparticles with potential use as active food packaging material. J Appl Microbiol 117:972-983

Nakagawa K (2014) Nano- and microencapsulation of flavor in food systems. In: Kwak HS (ed) Nano- and microencapsulation for foods. Wiley, Oxford, pp 249-272

Nakayama A, Kawasaki N, Maeda Y, Arvanitoyannis I, Ariba S, Yamamoto N (1997) Study of biodegradability of poly (3- valerolactone-co-L-lactide). J Appl Polym Sci 66:741-748

Nam JM, Thaxton CS, Mirkin CA (2003) Nanoparticle-based bio- bar codes for the ultrasensitive detection of proteins. Science 301(5641):1884-1886

Nano-enabled Packaging Market by Type (2019) (Active, Intelligent, and Others) and Industry Vertical (Food \& Beverages, Pharmaceuticals, Cosmetics, Consumer Electronics, and Others) Global Opportunity Analysis and Industry Forecast, 2018-2025. https://www.alliedmarketresearch.com/nano-enabled-packaging-market. Accessed on 21 May 2019)

Nanowerk Nanotechnology in Food (2019). https://www.nanowerk.com/nanotechnology-in-food. php. Accessed 13 May 2019

Neethirajan S, Jayas DS (2011) Nanotechnology for the food and bioprocessing industries. Food Bioprocess Technol 4:39-47 
Ntim SA, Thomas TA, Begley TH, Noonan GO (2015) Characterisation and potential migration of silver nanoparticles from commercially available polymeric food contact materials. Food Addit Contam 32:1003-1011

Oberdörster G (2001) Pulmonary effects of inhaled ultrafine particles. Int Arch Occup Einviron Health 74:1-8

Oconnell M, Valdora G, Peltzer G, Negri RM (2001) A practical approach for fish freshness determinations using a portable electronic nose. Sensors Actuators B Chem 80(2):149-154

Otles S, Yalcin B (2010) Nano-biosensors as new tool for detection of food quality and safety. LogForum 6(4):67-70

Pardo M, Niederjaufner G, Benussi G, Comini E, Faglia G, Sberveglieri G, Holmberg M, Lundstrom I (2000) Data preprocessing enhances the classification of different brands of Espresso coffee with an electronic nose. Sensors Actuators B Chem 69:397-403

Pavlath AE, Orts W (2009) Edible films and coatings: why, what, and how? In: Embuscado ME, Huber KC (eds) Edible films and coatings for food applications. Springer, Berlin. https://doi. org/10.1007/978-0-387-92824-11

Pehanich M (2006) Small gains in processing and packaging. Food Process 11:46-48

Peter A, Tegla D, Giurgiulescu L, Cozmuta AM, Nicula C, Cozmuta LM, Vagelas I (2015) Development of $\mathrm{Ag} / \mathrm{TiO}_{2}-\mathrm{SiO}_{2}$-coated food packaging film and its role in preservation of green lettuce during storage. Carpathian J Food Sci Technol 7:88-96

Peter A, Mihaly-Cozmuta L, Mihaly-Cozmuta A, Nicula C, Ziemkowska W, Basiak D et al (2016) Changes in the microbiological and chemical characteristics of white bread during storage in paper packages modified with $\mathrm{Ag} / \mathrm{TiO}_{2}-\mathrm{SiO}_{2}, \mathrm{Ag} / \mathrm{N}-\mathrm{TiO}_{2}$ or Au/TiO . Food Chem 197:790-798

Pietroiusti A, Magrini A, Campagnolo L (2016) New frontiers in nanotoxicology: Gutmicrobiota/ microbiome-mediated effects of engineered nanomaterials. Toxicol Appl Pharmacol 299:90-95

Pool H, Quintanar D, Figueroa JDD, Mano CM, Bechara JEH, Godínez LA, Mendoza S (2012) Antioxidant effects of quercetin and catechin encapsulated into PLGA nanoparticles. J Nanomater 2012:1-12. https://doi.org/10.1155/2012/145380

Pradhan N, Singh S, Ojha N, Shrivastava A, Barla A, Rai V, Bose S (2015) Facets of nanotechnology as seen in food processing, packaging, and preservation industry. Biomed Res Int 2015:117. https://doi.org/10.1155/2015/365672

Qiao H, Liu W, Gu H, Wang D, Wang Y (2015) The transport and deposition of nanoparticles in respiratory system by inhalation. J Nanomater 2015:1-8. https://doi.org/10.1155/2015/394507

Quintavalla S, Vicini L (2002) Antimicrobial food packaging in meat industry. Meat Sci 62:373-380

Rai M, Ingle AP, Gupta I, Pandit R, Paralikar P, Gade A, Chaud MV et al (2018) Smart nanopackaging for the enhancement of food shelf life. Environ Chem Lett 17:277-290. https://doi. org/10.1007/s10311-018-0794-8

Ramos M, Jiménez A, Peltzer M, Garrigós MC (2014) Development of novel nano-biocomposite antioxidant films based on poly (lactic acid) and thymol for active packaging. Food Chem 162:149-155. https://doi.org/10.1016/j.foodchem.2014.04.026

Rani A, Singh R, Shukla G (2017) Nanotechnology in agriculture and food sector. In: Applications of nanotechnology: an introduction. Horizon Books, New Delhi, p 29

Ranjan S, Dasgupta N, Chakraborty AR, Melvin SS, Shanker R, Ramalingam C, Kumar A (2014) Nanoscience and nanotechnologies in food industries: opportunities and research trends. J Nanopart Res 16(6):2464. https://doi.org/10.1007/s11051-014-2464-5

Rashidi L, Khosravi-Darani K (2011) The applications of nanotechnology in food industry. Crit Rev Food Sci Nutr 51:723-730

Ravichandran R (2010) Nanotechnology applications in food and food processing: innovative green approaches, opportunities and uncertainties for global market. Int J Green Nanotechnol Phys Chem 1:72-96

Ray SS, Bousmina M (2005) Biodegradable polymers and their layered silicate nanocomposites: in greening the 21st century materials world. Prog Mater Sci 50(8):962-1079 
Robinson DKR, Morrison MJ (2010) Nanotechnologies for food packaging: reporting the science and technology research trends. Report for the observatory NANO. Available from: http://www.observatorynano.eu/project/filesystem/files/Food\%20Packaging\%20Report\%20 2010\%20DKR\%20Robinson.pdf

Rong J, Niu Z, Lee LA, Wang Q (2011) Chemistry and materials development of protein-based nanoparticles. Compr Nanosci Technol 2:153-174

Sanguansri P, Augustin MA (2006) Nanoscale materials development - a food industry perspective. Trends Food Sci Technol 17(10):547-556

Sekhon BS (2010) Food nanotechnology - an overview. Nanotechnol Sci Appl 3:1-15

Setkus A (2002) Heterogeneous reaction rate based description of the response kinetics in metal oxide gas sensors. Sensors Actuators 87:346-357

Severino P, Andreani T, Macedo AS, Fangueiro JF, Santana MHA, Silva AM, Souto EB (2012) Current state-of-art and new trends on lipid nanoparticles (SLN and NLC) for oral drug delivery. J Drug Deliv 2012:1-10. https://doi.org/10.1155/2012/750891

Sharma C, Dhiman R, Rokana N, Panwar H (2017) Nanotechnology: an untapped resource for food packaging. Front Microbiol 8:1735. https://doi.org/10.3389/fmicb.2017.01735

Shi H, Magaye R, Castranova V, Zhao J (2013) Titanium dioxide nanoparticles: a review of current toxicological data. Part Fibre Toxicol 10:1-33. https://doi.org/10.1186/1743-8977-10-15

Shit SC, Shah PM (2014) Edible polymers: challenges and opportunities. J Polym 2014:1-13. https://doi.org/10.1155/2014/427259

Sinha N, Ma J, Yeow JTW (2006) Carbon nanotube-based sensors. Nanosci Nanotechnol 1(6):573-590

Sirelkhatim A, Mahmud S, Seeni A, Noor HMK, Ling CA, Bakhori SKM, Hasan H et al (2015) Review on zinc oxide nanoparticles: antibacterial activity and toxicity mechanism. Nano Micro Lett 7:219-242

Srinivas K (2016) The role of nanomaterials in food industry with advantages and risks on human health. Res J Pharm, Biol Chem Sci 7(5):2382-2399

Suker DK, Albadran RM (2013) Cytotoxic effects of titanium dioxide nanoparticles on rat embryo fibroblast REF-3 cell line in vitro. Eur J Exp Biol 3(1):354-363

Suppakul P, Miltz J, Sonneveld K, Bigger SW (2003) Active packaging technologies with an emphasis on antimicrobial packaging and its application. J Food Sci 68(2):408-420

Tak L, Singh S, Bais B, Pandey A, Soni A, Singh PK (2015) Nanotechnology: an advanced way to meat processing and packaging. Glacier J Sci Res:1-16

Tang D, Sauceda JC, Lin Z, Ott S, Basova E, Goryacheva I, Biselli S et al (2009) Magnetic nanogold microspheres-based lateral-flow immunodipstick for rapid detection of aflatoxin $\mathrm{B}_{2}$ in food. Biosens Bioelectron 25(2):514-518

Tankhiwale R, Bajpai SK (2012) Preparation, characterization and antibacterial applications of ZnO-nanoparticles coated polyethylene films for food packaging. Colloids Surf B: Biointerfaces 90:16-20

Taylor TM, Davidson PM, Bruce BD, Weiss J (2005) Liposomal nanocapsules in food science and agriculture. Crit Rev Food Sci Nutr 45:587-605

Van der Walle GA, de Koning GJ, Weusthuis RA, Eggink G (2001) Properties, modifications and applications of biopolyesters. Adv Biochem Eng Biotechnol 71:263-291

Venkatasubbu GD, Baskar R, Anusuya T, Seshan CA, Chelliah R (2016) Toxicity mechanism of titanium dioxide and zinc oxide nanoparticles against food pathogens. Colloids Surf B: Biointerfaces 148:600-606

Verma S, Gupta S (2017) Nanotechnology and food science: tomorrow design the food. Int J Curr Microbiol App Sci 6(9):3553-3561

Vidhyalakshmi R, Bhakyaraj R, Subhasree RS (2009) Encapsulation the future of probiotics- a review. Adv Biol Res 3(3-4):96-103

Weir A, Westerhoff P, Fabricius L, Hristovski K, Goetz VN (2012) Titanium dioxide nanoparticles in food and personal care products. Environ Sci Technol 46:2242-2250 
Wesley SJ, Raja P, Sunder Raj AA, Tiroutchelvamae D (2014) Review on- nanotechnology applications in food packaging and safety. Int J Eng Res 3:645-651

Wooster TJ (2010) Nanoemulsions for Beverage Applications. Nano and Microtechnologies in the Food and Health Food Industries, 25th and 26th October, Amsterdam, The Netherlands. Available from: www.nano.org.uk/conferences/food_health/abstracts.html. Accessed $26 \mathrm{Feb}$ 2010

World Bank (2017) ICT in agriculture (updated edition): connecting smallholders to knowledge, networks and institutions. World Bank Publications, Washington, DC, p 303

Wu HH, Yin JJ, Wamer WG, Zeng MY, Lo YM (2014) Reactive oxygen species related activities of nano-iron metal and nano-iron oxides. J Food Drug Anal 22:86-89

Yalcin B, Otles S (2010) Nanobiosensor and food pathogen interaction mechanisms. Elec J Env Agricult Food Chem 9(7):1257-1273

Yam KL, Takhistov PT, Miltz J (2005) Intelligent packaging: concepts and applications. J Food Sci 70:R1-R10

Yemmireddy VK, Hung Y-C (2015) Effect of binder on the physical stability and bactericidal property of titanium dioxide $\left(\mathrm{TiO}_{2}\right)$ nanocoatings on food contact surfaces. Food Control 57:82-88

Youssef AM (2013) Polymer nanocomposites as a new trend for packaging applications. PolymPlast Technol Eng 52:635-660

Yu H, Park JY, Kwon CW, Hong SC, Park KM, Chang PS (2018) An overview of nanotechnology in food science: preparative methods, practical applications, and safety. J Chem 2018:1-10. https://doi.org/10.1155/2018/5427978

Yuan Y, Gao Y, Zhao J, Mao L (2008) Characterization and stability evaluation of $\beta$-carotene nanoemulsions prepared by high pressure homogenization under various emulsifying conditions. Food Res Int 41(1):61-68 